\title{
Digital Health Information Disparities in Older Adults: a Mixed Methods Study
}

\author{
Ruth M. Tappen ${ }^{1} \cdot$ Mary E. Cooley ${ }^{2} \cdot$ Roger Luckmann $^{3} \cdot$ Somi Panday $^{1}$ \\ Received: 15 July 2020 / Revised: 18 November 2020 / Accepted: 19 November 2020 / Published online: 7 January 2021 \\ (C) W. Montague Cobb-NMA Health Institute 2021
}

\begin{abstract}
Important health information including disease prevention and chronic disease self-management is increasingly packaged for digital use. The purpose of this sequential explanatory mixed methods study was to describe the extent of computer ownership, Internet access, and digital health information use in an ethnically diverse sample of older adults, comparing ownership, access, and use of digital health information (DHI) across ethnic groups and identifying the factors associated with them quantitatively. Significant differences in computer ownership, Internet access, and DHI use were found across ethnic groups (African American, Afro-Caribbean, Hispanic American, and European American). Logistic regression identified older age, less education, lower income, and minority group membership as significant predictors of limited DHI use. Older African Americans were one-fifth as likely to own a computer than were European Americans; Hispanic Americans were one-half as likely to have access to the Internet. We then conducted a series of focus groups which highlighted differences across ethnic groups. Participants in the African American/Afro-Caribbean group expressed frustration with lack of access to DHI but appreciation for alternative sources of information. Hispanic Americans critiqued information received from providers and drug inserts, some suggesting that a positive attitude and trust in God also contributed to getting well. European American participants evaluated various DHI websites, looking to providers for help in applying information to their personal situation. As the development and use of DHI continue, parallel efforts to increase access to DHI among economically disadvantaged and minority older adults are critical to prevent further disfranchisement.
\end{abstract}

Keywords Digital health information $\cdot$ Digital divide $\cdot$ Internet access $\cdot$ Older adults $\cdot$ Minority health

Engaging patients in effective self-care management and shared decision-making requires a well-informed patient $[1$, 2]. Increasingly, the needed health-related information and health decision-making guidance are packaged and made available digitally. Digital technology includes the electronic tools, systems, devices, and resources that generate, store, and process data [3]. Digital health technologies include mobile health, wearable devices, telehealth, telemedicine, electronic health records, patient portals, and the like [4]. Data stored on computers or other electronic devices is known as digital

Ruth M. Tappen

rtappen@health.fau.edu

1 Florida Atlantic University - Christine E. Lynn College of Nursing, Boca Raton, FL, USA

2 Phyllis F. Cantor Center, Research in Nursing and Patient Care, Dana-Farber Cancer Institute, Boston, MA, USA

3 Department of Family Medicine and Community Health, University of Massachusetts Medical School, Worchester, MA, USA information, whereas the term digital health information (DHI) refers to data (information) related to healthcare stored, processed, and/or accessed on electronic devices with the goal of improving the patient experience, promoting and maintaining health, and improving outcomes of care [5-8]. The use of technology to distribute and exchange health information digitally has several advantages: not only can it be interactive but also efficient in delivering important information to large numbers of individuals.

Social Determinants of Health The social determinants of health framework provides the theoretical underpinnings of this study. These determinants are various elements of the social environments into which people are born, live, work, and grow old. An individual's health is determined in part by access to social and economic opportunities which are prominent among the identified social determinants of health [9]. Income and education, for example, are strong predictors of variations in health. Individuals with low income and education levels often develop chronic illnesses in middle age that 
are not commonly found in those with higher income and education until decades later. Members of these disadvantaged groups have also been found to be more likely to engage in high risk behaviors and less likely to engage in health promoting behaviors [10].

Furthermore, these social determinants have been found to be patterned by race and ethnicity, producing health disparities related to greater exposure to environmental stressors and other contributors to disease. These disparities themselves have arisen from the larger historical context, in particular the long standing systemic racism that has shaped the environment and access to healthcare for people of color [11]. Many of these disparities continue today and are hypothesized to be reflected in computer ownership, access to the Internet, and use of digital health information.

Related Research Access to digital health information is still far from universal, particularly in older populations and especially for those who are economically disadvantaged and/or members of an ethnic minority group. Czaja and colleagues found less computer experience in African Americans and Hispanic Americans than in European Americans in a sample of 1204 individuals aged 19 to 91 years [12]. Those who were older, members of a minority group, and less educated reported less information technology use. Similarly, from their review of NHATS (National Health and Aging Trends Study) data on community-dwelling Medicare beneficiaries from 2011 to 2014, Levine and colleagues concluded that digital health information still has not reached most older adults [13]. In their NHATS sample of 7609 older adults (average age 75, $57 \%$ women and $43 \%$ men), $76 \%$ reported they used mobile phones, and $63 \%$ used computers, but only $43 \%$ used the Internet for any purpose. Far fewer used any digital health technology: $16 \%$ for health-related information, $8 \%$ for prescriptions, and $7 \%$ to communicate with providers digitally. The researchers found only small increases in use from 2011 to 2014 and commented that reliance on data about general population use of the Internet is likely to result in overestimation of the use of digital health technology by older adults. The NHATS data also point to socioeconomically based disparities: higher income and educational levels were associated with greater use of digital health technology. Those who were older, in poor health, divorced, Black, or Latino reported lower use [13].

Widely differing degrees of Internet access and use are likewise found in smaller, more focused samples, reflecting differences across socioeconomic and ethnic/racial groups. For example, in a primarily Asian (Chinese and Korean), low-income immigrant group of older adults, Jung and colleagues found $59 \%$ reported they had never used a computer at all [14]. Similarly, Choi and Di Nitto found that only $17 \%$ of 764 low-income, homebound older adults used the Internet. An additional $14 \%$ reported they had stopped using it due to the effects of disability, pain, or vision loss [15]. The majority of those who were previous users reported they could not afford an Internet subscription or new electronic device. Those who had never used the Internet were more likely to be Black or Hispanic and have lower incomes. The researchers noted that relatively few participants used the Internet despite the potential benefits of accessing health-related information [15]. Pena-Purcell found lower Internet health information seeking among Hispanics than non-Hispanic Whites [16]. Nevertheless, the Hispanic participants were positive about the potential benefits of using digital health information and likely to agree that DHI improves understanding of medical conditions and treatment, gives patients confidence to talk to their provider about health concerns, and helps them get treatment they would not otherwise receive.

Swed and colleagues conducted a similar analysis of data from the National Center for Veterans Analysis and Statistics (NCVAS) on a nationally representative sample of 8509 veterans, $91 \%$ of whom were male, $11 \%$ Black [17]. While they too found similar determinants of Internet usage, their results also provide empirical support for the importance of addressing this digital divide: veterans who used the Internet only once a month or less had $81 \%$ higher odds of reporting poor health independent of socioeconomic factors.

In stark contrast to the findings among older, less educated, less financially secure individuals, Tomko and colleagues found that $91 \%$ of their somewhat younger, relatively welleducated (60\% had at least some college) sample aged 45 to 70 had Internet access [18]. However, when asked to make a choice between a digital or print decision aid for prostate cancer screening, a larger number preferred receiving it in print rather than digitally (52\% vs. $37 \%$ ). Race (White vs non-White) was a significant predictor of use of the decision aid $(\mathrm{OR}=2.43,95 \% \mathrm{CI}: 1.77,3.35)$ as were education and their print vs web-based information preference [18].

There is considerable evidence of a digital health information divide between older and younger populations and, within the older population, between lower- and higher-income groups and between minority and nonminority populations [19]. Few studies, however, have qualitatively explored reasons for this persistent digital health information disparity. These reasons may provide new insights and guidance for efforts to eliminate this critical disparity. The aims of this mixed methods study were to describe the extent of computer ownership, Internet access, and digital health information use in older African Americans, Afro-Caribbeans, Hispanic Americans, and European Americans quantitatively; identify factors related to electronic device ownership, Internet access, and digital health information use; and explore qualitatively the reasons for any differences found quantitatively employing a series of focus groups. 


\section{Design and Methods}

Design A sequential explanatory mixed methods approach in which quantitative data is obtained and analyzed first, and the subsequent qualitative data are collected to help explain the quantitative results was employed for this study [20]. The quantitative data were collected as part of the Healthy Aging Research Initiative (HARI), an in-depth survey of the health and wellbeing of multiethnic community-dwelling older adults in South Florida. The survey included questions addressing computer ownership, Internet access, and digital health information use. Upon completion of this study, three HARI data collection sites, a low-income senior housing site and two service agencies, were used to conduct four focus groups on Internet access and digital health information use to further explore and better understand the reasons for differences in the use of digital health information across minority and non-minority older adults.

Sites The HARI quantitative data were collected from lowincome housing sites, senior centers, churches, and other service agencies in Miami-Dade, Broward, and Palm Beach counties of South Florida. The four focus groups were conducted at three sites selected for their high concentrations of potential participants representing the four predominant ethnic groups in South Florida, African Americans, AfroCaribbeans, Hispanic Americans, and European Americans. Residents of the low-income senior housing complex selected were primarily African American and Afro-Caribbean. The Miami-Dade county service agency included a senior center attended by primarily low- to moderate-income monolingual (Spanish) Hispanic Americans. The third site was a Memory Center that offered a variety of counseling and support services in a relatively affluent community.
Sample Inclusion criteria for the HARI study were age $\geq$ 60 years, walking independently or with an assistive device, age and education-adjusted Mini-Mental State Examination score $\geq 23$, and self-reported identification with one of the four ethnic groups studied (African Americans, Afro-Caribbeans, Hispanic Americans, and European Americans) [21]. Altogether, 562 older adults provided information about their computer ownership, Internet access, and digital health information use in the survey. The sample included 100 African Americans, 113 Afro-Caribbeans, 129 Hispanic Americans, and 220 White non-Hispanic European Americans. Detailed sociodemographic data may be found in Table 1.

Forty-nine older adults participated in the focus groups. For the first focus group, there were 28 low-income African American and Afro- Caribbeans, aged 51 to 95 (average age 73 , SD 11), among which 7 were men and 21 were women. In the second focus group, there were 12 low- to middle-income Hispanic participants aged 66 to 86 (average age 72, SD 15) among which 2 were men and 10 were women; in the third and fourth group (which were conducted on consecutive days at the third site to accommodate participant schedules), there were 9 middle- to high-income European Americans, aged 65 to 84 (average age 73, SD 4.75), among which 4 were men and 5 were women.

\section{Data Collection}

- Quantitative Survey. In the HARI study, three to four separate interview sessions for assessment of physical and psychosocial status and health-related behaviors, including computer ownership and access to and use of the Internet for health-related purposes, were conducted by bilingual English-Spanish and English-Creole members of the research team. Participants were asked if they

Table 1 Comparison of ethnic groups: sociodemographic characteristics of quantitative study sample

\begin{tabular}{|c|c|c|c|c|c|c|c|c|c|c|}
\hline & \multicolumn{2}{|c|}{ African American } & \multicolumn{2}{|c|}{ Afro-Caribbean } & \multicolumn{2}{|c|}{ Hispanic American } & \multicolumn{2}{|c|}{ European American } & \multirow[b]{2}{*}{$F$} & \multirow[b]{2}{*}{$p$} \\
\hline & M & SD & M & SD & M & SD & M & SD & & \\
\hline Age & 71.06 & 7.08 & 72.47 & 7.73 & 72.61 & 7.29 & 76.60 & 8.92 & 14.77 & $<0.0001$ \\
\hline Years of education & 13.11 & 3.83 & 11.34 & 5.09 & 10.83 & 5.28 & 15.50 & 3.76 & 37.29 & $<0.0001$ \\
\hline Gender & \multicolumn{2}{|l|}{$n(\%)$} & \multicolumn{2}{|l|}{$n(\%)$} & \multicolumn{2}{|l|}{$n(\%)$} & \multicolumn{2}{|l|}{$n(\%)$} & $\chi^{2}$ & $p$ \\
\hline Male & \multirow{2}{*}{\multicolumn{2}{|c|}{$\begin{array}{l}18(18 \%) \\
82(82 \%)\end{array}$}} & \multirow{2}{*}{\multicolumn{2}{|c|}{$\begin{array}{l}30(27 \%) \\
83(73 \%)\end{array}$}} & \multirow{2}{*}{\multicolumn{2}{|c|}{$\begin{array}{l}24(19 \%) \\
105(81 \%)\end{array}$}} & \multirow{2}{*}{\multicolumn{2}{|c|}{$\begin{array}{l}85(39 \%) \\
135(61 \%)\end{array}$}} & 23.10 & $<0.0001$ \\
\hline Female & & & & & & & & & & \\
\hline \multicolumn{11}{|l|}{ Born in the USA } \\
\hline Yes & \multicolumn{2}{|l|}{$99(99 \%)$} & \multicolumn{2}{|l|}{$21(19 \%)$} & \multicolumn{2}{|l|}{$11(9 \%)$} & \multicolumn{2}{|l|}{$201(91 \%)$} & 373.76 & $<0.0001$ \\
\hline No & \multicolumn{2}{|l|}{$1(1 \%)$} & \multicolumn{2}{|l|}{$92(81 \%)$} & \multicolumn{2}{|l|}{$118(91 \%)$} & \multicolumn{2}{|l|}{$19(9 \%)$} & & \\
\hline \multicolumn{11}{|l|}{ Medicaid assistance } \\
\hline Yes & \multicolumn{2}{|l|}{$24(24 \%)$} & \multicolumn{2}{|l|}{$34(30 \%)$} & \multicolumn{2}{|l|}{$53(41 \%)$} & \multicolumn{2}{|l|}{$11(5 \%)$} & 69.61 & $<0.0001$ \\
\hline No & \multicolumn{2}{|l|}{$76(76 \%)$} & \multicolumn{2}{|l|}{$79(70 \%)$} & \multicolumn{2}{|l|}{$76(59 \%)$} & \multicolumn{2}{|l|}{$209(95 \%)$} & & \\
\hline
\end{tabular}

$M$ mean, $S D$ standard deviation 
owned a computer, laptop, or tablet and had accessed the Internet for any purpose or searched for health-related information online. If they had not used the Internet to search for health-related information, they were asked why not and given a list of the most common reasons from which they could select as many as were relevant.

- Focus Groups. Flyers announcing the focus groups were posted, and participants for the focus group were recruited by staff at the three participating sites. At two sites, participants received a small gift card for their participation, but at the third site (groups 3 and 4), they were offered a light lunch based on the recommendations of agency staff. The same approach to introducing the subject under discussion was used with each group. The 60-min meetings began with a welcome, introduction of the group leaders, and an explanation of the purpose of the group and verbal consent including the recording of the sessions and participants' rights to participate to the extent they wished or withdraw as approved by the University Committee for the Protection of Human Subjects (IRB). To provide context for the discussion, the groups were shown two examples of health-related information that can be found online: GERD: Which treatment should I use? and a comparison of the costs of commonly prescribed medications for type II diabetes [22, 23]. They were then asked what experiences they had, if any, with similar materials, as well as their opinion of them and their thoughts regarding how, what, when, and where this information should be made available to them, their families, friends, and neighbors. Participants were encouraged to respond freely and to share their experiences with digital health-related information with the group. A bilingual native Spanish speaker led the discussion with the Hispanic group in Spanish (primary language of all these older participants in the second group). The discussion in Spanish was recorded, transcribed, and translated and then back translated by bilingual native speakers. A bilingual native Haitian Creole speaker led the African American/Afro-Caribbean group in both English and Haitian Creole and translated simultaneously, so participants could understand each other. The translations were recorded by a second group leader and later transcribed and checked for accuracy by a third team member. The third and fourth focus groups (the European American participants) were conducted in English. A second group leader audio-recorded participant comments which were later transcribed and checked for accuracy by the group leaders prior to analysis.

Data Analysis Sociodemographic characteristics of the HARI sample are reported as descriptive statistics. Reports of computer ownership, Internet access, and digital health information use were compared across ethnic groups using the chi- square statistic for categorical data and analysis of variance for continuous variables. The sociodemographic factors associated with computer ownership and Internet and digital information use were evaluated using logistic regression.

Thematic and pattern analysis of the focus group data was done using the approach described by Miles, Huberman, and Saldaña employing multiple cycles of coding for category, theme, and pattern and comparing these within and across the four focus groups followed by interpretation and integration with the quantitative results $[20,24]$. This was done by the first author and then reviewed and revised in discussion with the members of the research team based on their reading of the focus group transcripts. Differences in interpretation were reconciled through discussion by the team until consensus was achieved. The rigor of the qualitative analysis was addressed by the maintenance of a detailed audit trail and review of the completed summary by a focus group leader and/or translator. Negative case analysis led to the identification of important differences across the four focus groups.

\section{Results}

Community Sample Sixty percent $(n=338)$ of the community survey sample reported that they owned some type of computer, whether a desktop, laptop, or tablet. Close to one-half (49\%, $n=278$ ) of the 562 older adults interviewed indicated that they used the Internet. The number dropped to $38 \%$ ( $n=$ 211) when they were asked if they used health-related information obtained electronically. When asked why they did not use the Internet, the answers varied considerably from one person to another. Sixty-four (23\%) of the 284 participants who did not use the Internet reported that they had never learned how or never tried it. A smaller number $(n=22,8 \%)$ responded affirmatively when asked if they felt intimidated by computers. Small numbers reported they had physical problems $(n=2)$, did not trust the information $(n=2)$, or were concerned about privacy issues when using the Internet $(n=$ $2)$. Thirty-eight $(13 \%)$ indicated they were not interested in using computers or the Internet, and $28(10 \%)$ indicated they would leave it to their providers to provide them with the health information they needed. The remainder did not select a particular reason why they did not use the Internet to access digital health information.

Ethnic Group Differences There were significant differences in Internet access by ethnic group membership. Sixty-eight percent $(n=151)$ of the European Americans reported frequent Internet access compared with $38 \%(n=38)$ of the African Americans, $31 \%(n=35)$ of the Afro-Caribbeans, and $42 \%$ $(n=54)$ of the Hispanic American participants $\left(\chi^{2}(N=\right.$ $562)=56.04, p<0.0001)$. A similar pattern with higher percentages was found in reported ownership of a computer. 
Seventy-nine percent $(n=174)$ of the European Americans reported that they owned a desktop, laptop, or tablet compared with 54\% $(n=54)$ of the African Americans, $44 \%(n=50)$ of the Afro-Caribbeans, and $46 \%(n=60)$ of the Hispanic American participants $\left(\chi^{2}(N=562)=56.43, p<0.0001\right)$. The reported use of the Internet for health-related information follows the same pattern but at lower percentages: $54 \%$ European Americans, 34\% African Americans, 26\% AfroCaribbeans, and 23\% Hispanic Americans reported affirmatively, a significant difference across these ethnic groups $\left(\chi^{2}(N=562)=42.86, p<0.0001\right)$. Across the total sample, those who were on Medicaid were significantly less likely to own a computer: one-third of those on Medicaid owned a computer, while two-thirds of those who were not on Medicaid owned a computer $\left(\chi^{2}(N=\right.$ $562)=48.64, p<0.0001)$.
Social Determinants Logistic regression was used to identify sociodemographic characteristics independently associated with computer ownership, Internet use, and the use of digital health information. Older age and lower levels of educational achievement predicted lower computer ownership, Internet access, and use of digital health-related information. Lower income as measured by receiving Medicaid also predicted lower computer ownership, Internet access, and use of health-related information online. Gender and immigrant status (not born in the USA) did not predict any of these. Ethnic group membership, however, predicted lower computer ownership and access to the Internet in the African American, Afro-Caribbean, and Hispanic groups. Less access to digital health-related information was predicted only by African American or Afro-Caribbean group membership, not Hispanic group membership (Table 2).
Table 2 Logistic regression: factors associated with the use of digital health technology

\begin{tabular}{|c|c|c|c|c|c|c|c|}
\hline & $B$ & $\mathrm{SE}_{b}$ & $\beta$ & Odds Ratio & \multicolumn{2}{|l|}{$95 \% \mathrm{CI}$} & $p$ \\
\hline \multicolumn{8}{|l|}{ Computer ownership* } \\
\hline Age & -0.09 & 0.0150 & -0.4320 & 0.910 & 0.883 & 0.937 & $<0.0001$ \\
\hline Years of education & 0.09 & 0.0247 & 0.2493 & 1.097 & 1.045 & 1.152 & 0.0002 \\
\hline Gender & -0.14 & 0.2403 & -0.0351 & 0.866 & 0.541 & 1.388 & 0.5507 \\
\hline Born in USA & 0.40 & 0.3629 & 0.1089 & 1.494 & 0.734 & 3.043 & 0.2685 \\
\hline African American & -1.61 & 0.3359 & -0.3427 & 0.198 & 0.103 & 0.383 & $<0.0001$ \\
\hline Afro-Caribbean & -1.41 & 0.4087 & -0.3074 & 0.243 & 0.109 & 0.542 & 0.0005 \\
\hline Hispanic & -1.19 & 0.4203 & -0.2807 & 0.303 & 0.133 & 0.690 & 0.0045 \\
\hline \multirow[t]{2}{*}{ Receiving Medicaid assistance } & -0.55 & 0.2512 & -0.1326 & 0.573 & 0.350 & 0.938 & 0.0268 \\
\hline & $B$ & $\mathrm{SE}_{b}$ & $\beta$ & Odds Ratio & \multicolumn{2}{|l|}{$95 \% \mathrm{CI}$} & $p$ \\
\hline \multicolumn{8}{|l|}{ Internet use* } \\
\hline Age & -0.09 & 0.0146 & -0.4028 & 0.916 & 0.890 & 0.942 & $<0.0001$ \\
\hline Years of education & 0.12 & 0.0257 & 0.3307 & 1.131 & 1.075 & 1.189 & $<0.0001$ \\
\hline Gender & -0.33 & 0.2370 & -0.0808 & 0.719 & 0.452 & 1.144 & 0.1638 \\
\hline Born in USA & 0.06 & 0.3541 & 0.0168 & 1.064 & 0.532 & 2.129 & 0.8611 \\
\hline African American & -1.62 & 0.3230 & -0.3433 & 0.198 & 0.105 & 0.372 & $<0.0001$ \\
\hline Afro-Caribbean & -1.55 & 0.3987 & -0.3383 & 0.211 & 0.097 & 0.461 & $<0.0001$ \\
\hline Hispanic & -0.81 & 0.4119 & -0.1913 & 0.443 & 0.198 & 0.993 & 0.0480 \\
\hline \multirow[t]{2}{*}{ Receiving Medicaid assistance } & -0.83 & 0.2773 & -0.1954 & 0.440 & 0.256 & 0.758 & 0.0031 \\
\hline & $B$ & $\mathrm{SE}_{b}$ & $\beta$ & Odds Ratio & \multicolumn{2}{|l|}{$95 \% \mathrm{CI}$} & $p$ \\
\hline \multicolumn{8}{|c|}{ Accessing health-related information online* } \\
\hline Age & -0.08 & 0.0145 & -0.3887 & 0.918 & 0.893 & 0.945 & $<0.0001$ \\
\hline Years of education & 0.14 & 0.0282 & 0.3851 & 1.154 & 1.092 & 1.220 & $<0.0001$ \\
\hline Gender & -0.14 & 0.2375 & -0.0349 & 0.867 & 0.544 & 1.381 & 0.5482 \\
\hline Born in USA & 0.42 & 0.3610 & 0.1158 & 1.533 & 0.755 & 3.110 & 0.2367 \\
\hline African American & -1.06 & 0.3155 & -0.2261 & 0.344 & 0.185 & 0.638 & 0.0007 \\
\hline Afro-Caribbean & -0.85 & 0.3995 & -0.1850 & 0.427 & 0.195 & 0.935 & 0.0332 \\
\hline Hispanic & -0.80 & 0.4255 & -0.1891 & 0.447 & 0.194 & 1.029 & 0.0585 \\
\hline Receiving Medicaid assistance & -0.74 & 0.3168 & -0.1781 & 0.474 & 0.255 & 0.881 & 0.0183 \\
\hline
\end{tabular}

* Reference group equals those who own a computer and use the Internet and digital health information. Odds ratios are reported for owning a computer, using the Internet, and using digital health information 
The odds of owning a computer or having access to the Internet were one-fifth as likely in the African American group as it was for European Americans and one-fourth as likely for the Afro-Caribbean group. The odds of Hispanic Americans owning a computer were one-third as likely and for having access to the Internet less than one-half as great as for the European Americans. Those who received Medicaid assistance were less than one-half as likely to use either the Internet or digital health information as were those who did not receive Medicaid and a little more than half as likely to own a computer (Table 2). These striking differences are reflected in comments from focus group participants.

Focus Groups Results from the focus groups are reported by group to highlight the different emphases of each discussion followed by a comparison of the themes and patterns across groups and finally a comparison with the quantitative results. Due to their small number and consistency in ethnic group membership and responses, results from groups 3 and 4, both European Americans, are reported together.

The first focus group was comprised of low-income African American and Afro-Caribbean older adults. Much of the discussion in group 1 is related to participants' very limited access to the Internet and alternatives to digital sources of health information (details may be found in Text Box 1).

\section{Text Box 1}

Group 1: Low-Income African American and AfroCaribbean Participants

Site: Low-Income Housing Community Room/Library

Only two of the 28 individuals (7\%) in this group owned an electronic device with access to the Internet: one laptop and one smartphone. Another participant reported she had bought a computer, but when she found it did not have Internet service, "I packed it back up" and returned it. The remainder said they had no access, but wished they had.

When asked, they reported that transportation to the county library where computers are available was possible but limited and difficult. Several thought their building should make computers available for resident use.

A major source of health-related information for many in group 1 was a monthly call by a nurse employed by their Medicare Advantage plan. "You can ask her anything", they said. The nurse would remind them of blood work that needed to be done and would ask if they needed transportation to their next appointment.

They also received information related to diagnosed problems from the same source by mail. Four said they read everything they received; others said they read most of it. One saved all of these mailings in a binder, another in a large box.

Other sources of health-related information mentioned were family, friends, drug inserts, and their healthcare providers. It was added that not all providers share much information. "You need to ask," they said.

When asked about radio, television, or newspapers as sources of health-related information, there was little response. When asked about the best way to get health-related information to them, the response was "mail it!"
The second focus group was comprised entirely of low- to moderate-income Spanish-speaking older adults. Much of the discussion in group 2 was related to patient-provider interactions, particularly provider guidance related to prescribed medications and how the participants responded to these interactions. Brief mentions were made of health-related information on the Internet (Text Box 2).

\section{Text Box 2}

Group 2: Low- to Moderate-Income Hispanic Americans Site: Senior Center Meeting Room

Provider recommendations were mentioned by most as the primary source of health-related information, "I do whatever the doctor says." One added that even though she was feeling really bad, her doctor said, "keep taking it" (the medication), so she did until a friend told her to stop.

Participants reported receiving "many papers" when they went to the doctor and that they did read them. Some also mentioned they would check the drug insert if they took medication and did not feel well afterward. However, several who were on multiple medications complained that they received a lot of information about them but that "with so many, how do you know which one is causing the problem?" One added, "I kind of gave up," trying to sort it out. Another added that their doctors should know if a medication is going to be all right for them. "The professional should know," they said, "we do not have that knowledge. If you start reading all that information, you will not take anything."

One participant who had many allergies said she would first take half a dose of a new medication to see how she reacts to it. "You get to know your body and know if something's wrong." One reported using the Internet to search for health-related information, "If I get a new medication I have my friend 'Google," 'but said her son (a healthcare professional) warned her about information from the Internet, that you do not know where it is coming from.

Reliance on the doctor for information was emphasized by members of the Hispanic focus group. Participants also referred to the power of the mind, having a "positive attitude" in helping them get well and stay well. One reported that since her problems were not too serious, she did not follow all of her doctor's recommendations and was happy with this approach. Another had cancer and did what the doctor recommended, adopting what the participant described as a positive attitude, i.e., "Ok, let us fix it." One said she would talk first with God before deciding what to do, and another reported consulting a friend who was a doctor. There was little mention of searching the Internet for information.

Groups 3 and 4 were comprised of middle- to high-income White, non-Hispanic European Americans. Much of the discussion is related to the variety of sources for health-related information they had accessed on the Internet. The quality of the information, how participants used it, and differentiation from consultations with providers as sources of information were discussed in some detail (Text Box 3).

\section{Text Box 3}

Groups 3 and 4: Moderate- to High-Income European Americans 
Site: Memory and Wellness Center Conference Room

Participants not only mentioned but also critiqued the usefulness of various websites, comparing their preferences and experiences across sites. They noted that some sites should not be considered reliable sources of information and that some were commercially supported, although not necessarily unhelpful.

Receiving information from medical providers was also discussed. Participants were critical of doctors who do not share information or who tell their patients "do not bother" to read about drugs and their side effects. One told a story of having a serious illness years ago and being given three treatment options from which to choose. "These days I'd have more questions, would do a lot of research, (you) cannot rely on the doctor." Another added that some doctors do not like it when you do your "homework" but that you are smart to do it anyway.

Group participants commented that they generally found packaged health-related information too general and that they were not specific to an individual situation. One participant said he had never been given a decision aid, but if he had, he would like it to be presented as a decision tree that had yes-no branches.

The value of hearing others' experiences with the same problem, whether through blogs, support groups, or with family and friends, was enthusiastically endorsed. "They understand" participants noted, in a way that others who have not had the experience cannot.

\section{Themes and Variations Across Four Major Ethnic Groups}

Although all of the focus group meetings opened in the same manner with the group leaders introducing the topic for discussion as planned, different emphases emerged quickly in each group. Across the groups, four themes emerged from the focus groups: barriers to accessing information from any source, degree of familiarity with digital health information, alternative sources of health-related information, and the role of providers as a source of information. Within group variations across those ethnically diverse groups are also identified.

- Barriers to Accessing Health Information from Any Source. The theme of barriers resonated most powerfully in group 1's African American and Afro-Caribbean participants, who expressed great frustration with the difficulties related to obtaining Internet access and digital health information. Several also mentioned preferring information in their primary language (primarily French and Haitian Creole in this group). Remarkably, no one in the Hispanic group (\#2) raised the language issue, perhaps due to apparently greater reliance on their providers for information and greater availability of printed and digital materials in Spanish. A third barrier was the approach of some providers, who were reported to engage primarily in one-way provider-to-patient communication and did not encourage patient-to-provider communication or an exchange between provider and patient. This was raised by participants in all but group 1.

- Familiarity with Digital Health Information. Across focus groups, all participants were aware that health-related information was available online. However, the differences in actual use of digital health information across groups were stark. The European Americans reported checking multiple websites for information, evaluating the source, and weighing the value of the information. The Hispanic participants reported a smattering of encounters with digital health information and feeling some caution regarding the accuracy of this information, in some instances reminded of this by friends or family members. The African American/Afro-Caribbean participants reported virtually no acquaintance with digital health information but expressed a strong desire to be able to access it. A number of websites were discussed in the European American groups 3 and 4; only Google search was mentioned in the Hispanic group 2. Virtually complete lack of access to the Internet or digital health information was reported by participants in the African American and Afro-Caribbean group 1.

- Alternative Sources of Information. Across the groups, a considerable number of alternative sources of healthrelated information were mentioned. Insurers provided calls from nurses to the insured and mailed printed material to many group 1 participants, both of which were valued and used by the participants. Friends were mentioned briefly by all groups, family by the African American/Afro-Caribbean and European American groups but again only briefly. Support groups were mentioned in the Hispanic and European American groups. Later in the discussion, the European Americans also mentioned blogs and similar online sources for exchanging experiences with people who, they said, understood how they felt. Television, radio, and newspapers were reported not to be significant sources of health information.

- Roles of Providers. Providers were identified as significant sources of information, indeed the primary or central source, particularly to the Hispanic Americans. Participants especially valued a provider's ability to relate standard information from printed or digital sources to the individual's specific situation. Those providers who did not provide enough information or who discouraged their patients from seeking information were viewed negatively.

- Patterns and Variations Across Ethnic Groups. Across the groups, interest in accessing digital health-related information was highest in the African American/AfroCaribbean and European American groups. Preferred sources varied across groups, with the Hispanic participants relying primarily on providers while most of the European Americans engaged in active searches for reputable sources of information but wanted their providers to relate that general information to their specific situation. 
The African American and Afro-Caribbean participants expressed appreciation of the printed materials they received and of opportunities to ask whatever they wanted of the nurse who called them. They expected direction rather than expanded explanations and individualized information from their providers. Maintaining a positive attitude and using prayer ("talking with God") to make health-related decisions were brought up only by Hispanic American participants. Expressed valuing of digital health information was strongest in the European American participants, weak in the Hispanic American participants, and a wished for goal in the African American and Afro-Caribbean participants, reinforcing evidence of the strikingly wide digital health information divide identified in the quantitative data. Most participants had received health-related information from their providers (the "many papers" referred to by the Hispanic American group) and insurers (the calls and mailed materials referred to by the African American and AfroCaribbean participants), but it did not include digital health information, even for the European Americans.

\section{Discussion}

The presence of a deep digital health divide within the older population was evident in both the community sample and focus groups. This divide was associated with age, amount of formal education, income, and ethnic group membership. Those individuals who were older, less educated, poorer, and/ or members of an ethnic minority group (African American, Afro-Caribbean, or Hispanic American) were up to five times less likely to have access to digital health information than were those who were younger and more highly educated, had a higher income, or were European Americans. These results are similar to those of Swed and colleagues, Levine and colleagues, and others who found low levels of access to digital health information in older, poorer, minority, and immigrant groups [13-15, 17].

The results of the focus group sessions shed some light on the effects of this disparity and highlight differences in response across the minority groups represented. Interest in obtaining Internet health-related information was highest in the African Americans, Afro-Caribbeans, and European Americans, moderate at best in the Hispanic American group. Ability to afford a device that allows Internet access differed greatly across groups and participants' expressed preferences for provider-patient information or more independent searches, and involvement in decision-making also varied considerably. Almost none ( 2 of 28 ) of the low-income African American and Afro-Caribbean participants in the first focus group had an Internet-enabled electronic device or convenient Internet access to digital health information. They expressed frustration with their lack of access and appreciation for the printed materials and telephone calls they received. The Hispanic American participants in the second focus group focused more on receiving information from their medical providers and the power of a positive attitude with mention of drug inserts, an occasional Internet search, support groups, and conversations with family and friends and for one, talking with God. In contrast, the European American group was Internet savvy, doing "homework" about their health concerns online, but also talking with friends, family, in support groups, and looking to their providers to relate the information to their personal situations.

Culture shapes individuals' expectations of care and of the patient-provider relationship [25]. The differences in concerns and preferences voiced in the focus groups suggest caution that we do not overgeneralize across minority groups. It has been suggested that Hispanic patients on the whole prefer a more traditional relationship with their providers which was evident in the focus group results [26]. This may be related to valuing personal relationships with providers and a concern that asking too many questions may jeopardize the relationship [26]. There is also evidence that a small but important segment of the frail older adult population is more likely than are younger adults to delegate health-related decisions to a trusted provider, potentially reducing their interest in seeking out digital health-related information [27]. Challenges associated with accessing and utilizing health-related information emerged from the focus group discussions: the complexity of sorting out information on multiple drugs, relating general health information to one's own situation, the uncertain accuracy of information on various websites, and the difficulty of raising questions with paternalistic providers who engage primarily in one-way provider to patient communication.

Implications The barriers identified here may be underappreciated by developers of health-related information, patient decision aids, and the many apps being developed for self-monitoring treatment of depression, exercise promotion, medication self-management, diabetes self-management, and the like. These can be especially helpful for older adults, a high proportion of whom have chronic conditions and could benefit from these new digital health applications if they can access and use them. At present, digital health technology development is outpacing parallel efforts to conquer the digital health divide.

Addressing this digital health divide in the older population requires attention at several levels. At the policy level, national connectivity plans are needed, and greater effort to provide universal Internet access needs to be made [28]. Municipal broadband networks can achieve this at the local level [29]. Eventually Internet service needs to be redefined as a necessity, not a luxury, a necessary utility like electricity and water 
or to become a free service supported by advertisements as are broadcast radio and television [28]. Not only does it need to be affordable but also adequate for the job. Some free Internet services have been plagued with slow speed, weak indoor signals, and high "installation" fees to subscribers as well as service cancelation fees, leaving many of those who cannot afford the cost of Internet service still disconnected and disenfranchised [30, 31]. The effects of the COVID-19 pandemic highlighted how essential access to the Internet and to digital health information is in all communities [30, 32]. New approaches were tested during school shutdowns when students and teachers could only connect virtually. Inexpensive laptops or tablets, mobile hot spots, and wireless gateways were made available to students without access, enabling full participation in their online classes [33]. Older adults who qualify for federal nutrition programs or Medicaid, live in public housing, or are veterans may qualify for programs providing low-cost computers and Internet access [34]. Free access at public sites such as community centers, libraries, and community rooms of senior living facilities can also be used to introduce people to Internet use and to provide training for those who are not computer literate. The training programs are especially helpful to those individuals who lack experience and/or are intimidated by the Internet and need education and support.

Healthcare providers can support their patients' transition from passive to active participants in their care including the use of digital health information. There are also indications in the comments of focus group participants that digital health technologies need to be more customized and culturally sensitive as well as available in the patients' primary language than they are currently. For the present, there is still an important role for print-based information as well [18].

Limitations The strengths of this study lie in the diversity of the sample, the breadth of the community survey questions, and the added depth of understanding gained from the focus group discussions. Limitations were the use of a convenience sample that may not be representative of the broader populations of interest and possible reluctance of focus group participants to raise some issues within a group. For example, barriers to access of digital health information such as cost or lower education, which were evident from the quantitative data, were not raised in the focus groups. These more personal concerns might have been voiced in individual interviews. Too, the differences across the ethnic groups clearly interact with, but are not entirely due to, the differences in income across the groups. Disentangling the complex factors that underlie these disparities is a challenging task [10].

Several questions remain about the digital health divide in the older population. While it is clear that there is a cultural effect, we need a better understanding of several additional issues: (1) perceptions of the use of technology and specifically health-related technologies, (2) expectations regarding the role of the older adult as an active participant in one's healthcare, (3) means for raising the levels of basic computer and health literacy which are needed to use digital health technology comfortably and effectively, and (4) individual preferences for the traditional patient-provider role vs being an activated, involved patient with a responsive provider. The individual factors that many affect readiness to use digital health information, i.e., technological readiness, were not fully addressed in this study and should be further explored [35]. A final challenge to researchers who are developing and testing new uses of digital health technology is the call from these participants for health information available in print, telephonically, and in other non-digital formats as well as digitally until such time as access to digital health information is universal.

\section{Conclusion}

The ultimate goal of most digital health information development is to have an informed patient [17]. It is time to place the patient in the center of integrated healthcare systems, not at the periphery with technology facilitating the operation of the system. Increasing use of digital health technologies, whether mobile (mHealth) apps to track diet or exercise, to provide information on the meaning of a particular symptom or on the treatment for a health concern, portals that allow patients access to their electronic health records, decision aids that prepare patients to discuss options with their providers, making telehealth appointments with providers and so forth, needlessly, though unintentionally, excludes, marginalizes, and disenfranchises those who are older, have low incomes, have low health literacy, and/or are members of minority groups $[6$, 36]. Until Internet access is universal, creative use of printed materials, telephone calls, in-person groups, family assistance, individual meetings, and mailings are needed for those disadvantaged and minority older adults who remain affected by this digital health information disparity.

Code Availability Not applicable.

Authors' Contributions The first three authors (Drs. Tappen, Mary E. Cooley, and Roger Luckmann) contributed to the study conception and design. Material preparation, data collection, and analysis were performed by Ruth Tappen. The first draft of the manuscript was written by Ruth Tappen and revised by Somi Panday. All four authors commented on the previous versions of the manuscript. All authors read and approved the final manuscript.

Funding This research was supported in part by a grant from the Patient-Centered Outcomes Research Institute (PCORI), Eugene Washington PCORI Engagement Award - EAIN-2276, University of Massachusetts Medical School, Engaging Stakeholders in Implementation of Decision Aids. 
Data Availability The survey data may be made available upon application.

\section{Compliance with Ethical Standards}

Conflict of Interest The authors declare that they have no conflicts of interest.

Ethics Approval All procedures performed in studies involving human participants were in accordance with the ethical standards of the institutional and/or national research committee and with the 1964 Helsinki Declaration and its later amendments or comparable ethical standards. The study was approved by the University's Committee for the Protection of Human Subjects (IRB).

Consent to Participate A written consent was obtained prior to participation in the survey, and verbal consent was obtained prior to participation in the focus groups.

\section{References}

1. McCormack B, McCance T. Person-centred practice in nursing and health care. West Sussex: John Wiley \& Sons, Ltd.; 2017.

2. Ottawa Hospital Research Institute. (2020) Patient decision aids. http://www.decisionaid.ohri.ca.

3. Victoria State Government - Education and Training. (2020, June 30). Digital Technologies. https://www.education.vic.gov.au/ school/teachers/teachingresources/discipline/technologies/Pages/ digitaltechnologies.aspx

4. Food and Drug Administration. (2020, June 30). Digital Health. https://www.fda.gov/medical-devices/digital-health

5. Assessment, O. T. (1992). Finding a balance: computer software, Intellectual Property and the Challenges of Technological Change.

6. Ronquillo, Y., Meyers, A., \& Korvek, S.J. (2020). Digital health StatPearls [Internet]. Retrieved from https://www.ncbi.nlm.nih. gov/books/NBK470260/

7. Leung V, Tharmalingam S, Cooper J, Charlebois M. Canadian community pharmacists' use of digital health technologies in practice. Canadian Pharmacists Journal/Revue des Pharmaciens du Canada. 2016;149(1):38-45.

8. Cotton, S.R., Seckin, G., Veselka-Bush, A. \& DeGreve, T. (2019, August). Technoscientific approach to understanding health and well-being: what does age tell us about digital knowledge? Paper presentation at the American Sociological Association Conference August, 2019, New York, N.Y. pp 1-43.

9. Secretary's Advisory Committee on Health Promotion and Disease Prevention Objectives for 2020. Social determinants of health. HealthyPeople.gov https:/www.healthypeople.gov/2010/hp2020/ default.asp

10. Williams DR, Jackson PB. Social sources of racial disparities in health. Health Aff. 2005;24(2):325-34.

11. Caldwell JT, Ford CL, Wallace SP, Wang MC, Takahashi LM. Intersection of living in a rural versus urban area and race/ ethnicity in explaining access to health care in the United States. Am J Public Health. 2016;106(8):1463-9.

12. Czaja SJ, Charness N, Fisk AD, Hertzog C, Nair SN, Rogers WA, et al. Factors predicting the use of technology: findings from the center for research and education on aging and technology enhancement (CREATE). Psychol Aging. 2006;21(2):333-52. https://doi. org/10.1037/0882-7974.21.2.333.
13. Levine DM, Lipsitz SR, Linder JA. Trends in seniors' use of digital health technology in the United States, 2011-2014. JAMA. 2016;316(5):538-40.

14. Jung, Y., Peng, W., Moran, M., Jin, S. A., McLaughlin, M., Cody, M... Silverstein, M. (2010). Low-income minority seniors' enrollment in a cybercafé: psychological barriers to crossing the digital divide. Educ Gerontol, 36(3), 193-212. doi:https://doi.org/10.1080/ 03601270903183313

15. Choi N, Di Nitto D. The digital divide among low-income homebound older adults: internet use patterns, eHealth literacy, and attitudes toward computer/internet use. J Med Internet Res. 2013;15(5):e93. https://doi.org/10.2196/jmir.2645.

16. Pena-Purcell N. Hispanics' use of internet health information: an exploratory study. Journal of the Medical Library Association: JMLA. 2008;96(2):101-7.

17. Swed O, McDevitt C, Butler JS. The digital divide and veteran's health: differences in self-reported health by internet usage. Armed Forces Soc. 2020;46(2):238-58.

18. Tomko C, Davis KM, Luta G, Krist AH, Woolf SH, Taylor KL. A comparison of web-based versus print-based decision aids for prostate cancer screening: participants' evaluation and utilization. J Gen Intern Med. 2015;30(1):33-42. https://doi.org/10.1007/s11606014-2994-7.

19. Hall A, Bernhardt J, Dodd V, Vollrath M. The digital health divide: evaluating online health information access and use among older adults. Health Educ Behav. 2015;42(2):202-9. https://doi.org/10. $1177 / 1090198114547815$.

20. Cresswell JW, Clark VLP. Designing and conducting mixed methods research. Los Angeles: Sage; 2018.

21. Folstein MF, Folstein SE, McHugh PR. Mini-mental state: a practical method for grading the state of patients for the clinician. J Psychiatr Res. 1975;12:189-98.

22. Healthwise (2015). GERD: which treatment should I use? https:// lancastergeneralhealth.org/Healthwise/Document.aspx?id= aa56508

23. Mayo Clinic (2015). GERD: Can certain medicines make it worse? Accessed 21, June 2020. https://www.mayoclinic.org/diseasesconditions/gerd/expert-answers/heartburn-gerd/faq-20058535

24. Miles MB, Huberman AM, Saldaña J. Qualitative data analysis: a methods source book. 4th ed. Thousand Oaks, CA: Sage; 2020.

25. Rowe, R. J., Kellam, C., \& Stott, E. (2014). Understanding provider/patient expectations of care in clinical encounters. Home Health Care Management \& Practice,26(1), 34-38. doi:https://doi. org/10.1177/1084822313502789.

26. Alegría M, Sribney W, Perez D, Laderman M, Keefe K. The role of patient activation on patient-provider communication and quality of care for US and foreign born Latino patients. J Gen Intern Med. 2009;24(3):534-41.

27. Tappen RM, Elkins D, Worch S, Weglinski M. Modes of decision making employed by nursing home residents and their families when confronted with potential hospital readmission. Res Gerontol Nurs. 2016;9:288-99. https://doi.org/10.3928/1940492120160920-01.

28. Sarpong, E. (2020). COVID-19 shows why internet access is a basic right. We must get everyone connected. Web Foundation. Accessed on November $2^{\text {nd }}, 2020$. https://webfoundation.org/ 2020/04/covid-19-shows-why-internet-access-is-a-basic-right-wemust-get-everyone-connected/

29. Lieberman, $M(2020)$. Internet access is a civil rights issue. Education week. Accessed November $1^{\text {st }}, 2020$. https://www. edweek.org/ew/articles/2020/09/23/internet-access-is-a-civilrights-issue.html

30. Kharif, O. (2006). Free wi-fi - at a price: plans by cities to provide low-cost wireless internet access could crimp sales for smaller providers and may spark a wave of consolidation. Bloomberg business week online. Retrieved from http://www.bloomberg.com/news/ 
articles/2006-08-16/free-wi-fi-at-a-pricebusinessweek-businessnews-stock-market-and-financial-advice

31. Jain, A. (2016, April 11). ValueWalk: Google fiber ending free internet access in Kansas City [Weblog post]. Retrieved from http://www.valuewalk.com/2016/04/google-fiber-ending-freeinternet/

32. Article19.org. (2020). Coronavirus: access to the Internet can be a matter if life and death during a pandemic. Accessed on November $5^{\text {th }}, 2020$. https://www.article19.org/resources/access-to-theinternet-can-be-a-matter-of-life-and-death-during-the-coronaviruspandemic/

33. García E, Weiss E, Engdahl L. Access to online learning amid coronavirus is far from universal, and children who are poor suffer from a digital divide. Working Economics Blog: Economic Policy
Institute; 2020. Retrieved from https://www.epi.org/blog/access-toonline-learning-amid-coronavirus-and-digital-divide/

34. Low-Income Internet Options. DecisionData.org. 2020. https:// decisiondata.org/low-income-internet-options/ Accessed 20 June 2020.

35. Blut M, Wang C. Technology readiness: a meta-analysis of conceptualizations of the construct and its impact on technology usage. J of the Acad Mark Sci. 2020;48:649-69.

36. Anderson KM, Olsen S. The promises perils of digital strategies in achieving health equity: workshop summary. Work: National Academies Press; 2016.

Publisher's Note Springer Nature remains neutral with regard to jurisdictional claims in published maps and institutional affiliations. 